\title{
Comparing Alteration Layer Characteristics of Ancient Hillfort Glasses Corroded in the Field and Laboratory
}

\author{
JAMES J. NEEWAy, CAROLYN I. PEARCE, LORENA
} NAVA-FARIAS, LORRAINE M. SEYMOUR, JOSE MARCIAL

${ }^{1}$ Pacific Northwest National Laboratory, Richland, WA, USA 99354 (james.neeway@pnnl.gov, carolyn.pearce@pnnl.gov, lorena.nava@pnnl.gov, lorraine.seymour@pnnl.gov, jose.marcial@pnnl.gov)

Corrosion rates of natural glasses are generally orders of magnitude slower than corrosion rates measured in the laboratory. Though several reasons have been postulated, including surface area changes and solution saturation differences, a comparison between the influence of the alteration layer in natural and lab samples has largely been ignored. This alteration layer can affect the corrosion rate of the material because it provides surface sites to control reactive transport reactions, species released from the pristine material must diffuse through it to reach the bulk fluid, and the chemistry of the pore solution is different than the bulk fluid. Thus, an understanding of the physical and chemical properties of alteration layers and how they differ between natural and laboratory samples is important in predicting the corrosion of a wide variety of glass materials.

For this study, we examine glass samples from a Swedish hillfort that have been altered in a near-surface environment for over 1,500 years. The samples have the unique characteristic of having been formed by granite fused together with molten amphibolite. Additionally, glasses with granitic or amphibolitic chemical compositions were prepared in the laboratory for use in chemical durability tests. The chemical durability of the various glassy materials was studied using common accelerated laboratory corrosion tests that were performed at high temperature $\left(\geq 90^{\circ} \mathrm{C}\right)$ and in hydraulically unsaturated and saturated environments for several months. At the end of the tests, the thickness and morphology of the alteration layers on the different glasses were compared with those observed on vitrified artifacts excavated from the hillfort site. This unique combination of archeological analogues and laboratory testing provides a basis for understanding rate controlling processes in the natural environment and laboratory. 